\title{
New insights into the zircon-reidite phase transition
}

\section{Claudia Stangarone ${ }^{1, \uparrow}$, Ross J. Angel ${ }^{1, *}$, Mauro Prencipe ${ }^{2}$, Boriana Mihailova ${ }^{3}$, AND MATTEO AlVARO ${ }^{1}$}

\author{
${ }^{1}$ Department of Earth and Environmental Sciences, University of Pavia, Via A. Ferrata 1, I-27100 Pavia, Italy \\ ${ }^{2}$ Earth Sciences Department, University of Torino, Via Valperga Caluso 35, I-10125 Torino, Italy \\ ${ }^{3}$ Department of Earth Sciences, University of Hamburg, Grindelallee 48, D-20146 Hamburg, Germany
}

\begin{abstract}
The structure, the elastic properties, and the Raman frequencies of the zircon and reidite polymorphs of $\mathrm{ZrSiO}_{4}$ were calculated as a function of hydrostatic pressure up to $30 \mathrm{GPa}$ using HF/DFT ab initio calculations at static equilibrium $(0 \mathrm{~K})$. The softening of a silent $\left(\mathrm{B}_{\mathrm{lu}}\right)$ mode of zircon leads to a phase transition to a "high-pressure-low-symmetry" (HPLS) $\mathrm{ZrSiO}_{4}$ polymorph with space group $\bar{I} \overline{4} 2 d$ and cell parameters $a=6.4512 \AA, c=5.9121 \AA$, and $V=246.05 \AA^{3}$ (at $20 \mathrm{GPa}$ ). The primary coordination of $\mathrm{SiO}_{4}$ and $\mathrm{ZrO}_{8}$ groups in the structure of zircon is maintained in the high-pressure phase, and the new phase deviates from that of zircon by the rotation of $\mathrm{SiO}_{4}$ tetrahedra and small distortions of the $\mathrm{ZrO}_{8}$ dodecahedra. The new polymorph is stable with respect to zircon at $20 \mathrm{GPa}$ and remains a dynamically stable structure up to at least $30 \mathrm{GPa}$. On pressure release, the new phase reverts back to the zircon structure and, therefore, cannot be quenched in experiments. In contrast, the transformation from zircon to reidite is reconstructive in nature and results in a first-order transition with a volume and density change of about $9 \%$. The calculated energies from the DFT simulations yield an equilibrium transition pressure of 9.13(1) $\mathrm{GPa}$ at $0 \mathrm{~K}$. Simulations of the Raman spectra of the three polymorphs at $20 \mathrm{GPa}$ show how they can be distinguished. In particular, the peak due to the lowest-energy $\mathrm{A}_{1}$ mode with a calculated wavenumber of $94 \mathrm{~cm}^{-1}$ is diagnostic of the HPLS phase because it does not overlap with any of the peaks of zircon or reidite.
\end{abstract}

Keywords: Zircon, reidite, phase transition, Raman spectroscopy, high pressure

\section{INTRODUCTION}

Zircon $\left(\mathrm{ZrSiO}_{4}\right.$, space group $\mathrm{I}_{1} /$ amd $)$ is an extremely stiff material, and upon meteorite bombardment shock microstructures form within it at pressures of $20 \mathrm{GPa}$ or more (Leroux et al. 1999). These microstructures remarkably survive subsequent metamorphism without being obliterated and, therefore, they can provide diagnostic criteria to identify impact structures (French 1998; French and Koeberl 2010; Wittmann et al. 2006). During shocks zircon may transform into the high-pressure scheelite-type polymorph reidite (space group $I 4_{1} / a$ ). Naturally occurring reidite was first identified using X-ray diffraction (XRD) in zircon grains from Eocene ejecta associated with the $\sim 90 \mathrm{~km}$ diameter, ca. 35.7 Ma Chesapeake Bay impact structure (Glass and Liu 2001; Glass et al. 2002) and subsequently in several other impact structures (Gucsik et al. 2004; Wittmann et al. 2006; Wittmann and Reimold 2009; Chen et al. 2013; Cavosie et al. 2015; Singleton et al. 2015; Reddy et al. 2015; Cavosie et al. 2018). Therefore, to study the origin of impact structures and to further constrain the impact conditions it is crucial to understand the stability relationships between zircon and its high-pressure polymorph reidite.

This phase transition from zircon to reidite has a volume decrease of about 9\% (e.g., Reid and Ringwood 1969; Ono et al. 2004a), which suggests that it is thermodynamically first-order.

\footnotetext{
* E-mail: ross.angel@unipv.it

$\dagger$ Present address: Institute for Planetary Research, Deutsches Zentrums für Luftund Raumfahrt, Rutherfordstraße 2, D-12489 Berlin, Germany.
}

Moreover, the topological differences in the atomic linkages indicate that the zircon-reidite phase transition is reconstructive, which is supported by ab initio calculations (e.g., Marqués et al. 2006; Dutta and Mandal 2012a). Because of the reconstructive nature of the zircon-reidite transformation, the equilibrium transition pressure is not well constrained. At elevated temperatures of $1000-1500 \mathrm{~K}$ the pressure-induced zircon-to-reidite phase transition occurs near 8 GPa (Reid and Ringwood 1969; Ono et al. 2004b). Several static loading experiments in diamond-anvil pressure cells at room temperature have shown the presence of reidite when the pressure is increased above 18-23 GPa (Knittle and Williams 1993; Van Westrenen et al. 2004; Morozova 2015). However, there seems to be a discrepancy between the detection of reidite by Raman spectroscopy in the samples compressed to ca. $20 \mathrm{GPa}$ and higher pressures at room temperature, and the results of X-ray diffraction that show evidence only of zircon (van Westrenen et al. 2004). On the other hand, shock wave studies found this transformation to occur at much higher pressures (30-50 GPa) (Liu 1979; Kusaba et al. 1986; Gucsik et al. 2004) and very quickly, at microsecond timescales. The latter observation favors a martensitic transformation mechanism for impact-produced reidite, since other solid-state mechanisms seem unlikely to operate on the nanosecond to seconds timescale of shock events because diffusion rates are too slow (Langenhorst and Deutsch 2012).

Therefore, to elucidate the pressure-induced structural transformations of zircon we have performed ab initio simulations of zircon and reidite to determine their structures, elastic behavior, 
phonon frequencies, and the energy curves as a function of pressure (up to $25 \mathrm{GPa}$ and $17 \mathrm{GPa}$, respectively) at $0 \mathrm{~K}$, which allows us to resolve the ambiguities in the experimental data. We also provide calculated Raman spectra that will aid in the identification of the polymorphs of zircon.

\section{METHODS}

Ab initio HF/DFT simulations were performed with the two most recent versions of the CRYSTAL code, CRYSTAL14 (Dovesi et al. 2014) and CRYSTAL17 (Dovesi et al. 2018), employing the hybrid Hamiltonian WC1LYP that is particularly suitable for the correct reproduction of the elastic and vibrational properties of crystals (e.g., Prencipe 2012; Aliatis et al. 2015; Stangarone et al. 2016, 2017). In this Hamiltonian the Wu-Cohen DFT-GGA exchange contribution (Wu and Cohen 2005) is corrected by mixing it with a percentage ( $16 \%$ ) of the exact non-local Hartree-Fock exchange. The correlation is described by the LYP functional (Lee et al. 1988). The localized contracted atomic basis sets used were Si 86-311G(1d) (Pascale et al. 2004) and 8-411G(2d) (Valenzano et al. 2006) for Si and O, respectively, and the Hay-Wadt (HAYW) small-core (SC) pseudopotential basis SC_HAYWSC-3111(32111df) (Sophia et al. 2013) for Zr. The basis sets were taken from the repository at the address http://www.crystal.unito.it/basis-sets.php. In CRYSTAL, the level of accuracy in evaluating the Coulomb and Hartree-Fock exchange series is controlled by five parameters (Dovesi et al. 2018), specified by the TOLINTEG keyword in CRYSTAL. These parameters were set to $8,8,8,8$, and 18 . Reciprocal space was sampled using a regular sublattice with a shrinking factor of 4 , corresponding to 24 independent $\boldsymbol{k}$ vectors in the irreducible part of the Brillouin zone. The exchange-correlation DFT contributions to the Fock matrix were evaluated by numerical integration over the unit-cell volume. Radial and angular points for the integration grid were generated through Gauss-Legendre radial quadrature and Lebedev two-dimensional angular point distributions. In the present work, a pruned grid with 75 radial and 974 angular points was used (see XLGRID keyword in the CRYSTAL manual). Such parameters defined grids of 17604 points in the unit cell for zircon and 32094 for reidite. A measure of the high numerical accuracy reached with the grids is the evaluation of the total number of electrons in the unit cell, by the numerical integration of the electron density over the cell volume. For zircon, we obtained 116.00003 electrons and for reidite 116.00013 , both out of 116 , for the reference static volume $(0 \mathrm{~K}$, with no zero-point vibrational effects included) at $0 \mathrm{GPa}$. The crystal structures were optimized on the basis of analytical energy gradients with respect to fractional atomic coordinates and unit-cell parameters (Doll et al. 2001; Civalleri et al. 2001). Default values were chosen for convergence of gradient components as well as nuclear displacements. For the optimized crystallographic structure, the calculation of all phonon modes in zircon was carried out at static equilibrium. Vibrational wavenumbers and normal modes were calculated within the limit of the harmonic approximation, by diagonalizing a mass-weighted Hessian matrix, whose elements are the second derivatives of the full potential of the crystal with respect to mass weighted atomic displacements. The first derivatives of the energy with respect to the atomic positions are calculated analytically (Doll et al. 2001), whereas the second derivatives are numerically calculated by setting the nuclear displacements to $0.003 \AA$ from the equilibrium positions. The phonon frequencies and the structural data (atom coordinates and unit-cell parameters) are reported in the deposited ${ }^{1}$ crystallographic information files (CIFs). Relative Raman intensities were computed using a fully analytical approach (Maschio et al. 2013) implemented in the CRYSTAL14 program. It combines analytical gradients (Doll et al. 2001) with solutions of first-order and second-order coupled perturbed Hartree-Fock/Kohn-Sham equations (Ferrero et al. 2008) for the linear and quadratic orbital responses to electric fields in the different Cartesian directions. The thresholds for convergence of the coupled perturbed equations were set to the default values (Dovesi et al. 2014). Simulations were performed at 10 pressures from 0 to $25 \mathrm{GPa}$ for zircon and 8 pressures to $17 \mathrm{GPa}$ for reidite. The $P$ - $V$ equations of state have been computed from these data with both CRYSTAL17, by using the fully automated scheme (option EOS), or with CRYSTAL14 by fitting the unit-cell volumes and pressures from the simulations with EosFit7c (Angel et al. 2014). Both methods yield the same results within numerical rounding errors.

\section{RESULTS AND DISCUSSION}

\section{Zircon structure}

The structure of zircon contains $\mathrm{Si}$ in tetrahedral coordination by oxygen, and $\mathrm{Zr}$ in eightfold coordination by oxygen in the form of a triangular-faced dodecahedron (sometimes called a sub-disphenoid). Four of the 18 edges of each of the $\mathrm{ZrO}_{8}$ polyhedra are shared with neighboring $\mathrm{ZrO}_{8}$ polyhedra to form a three-dimensional framework (Fig. 1a). A further two edges are shared with two $\mathrm{SiO}_{4}$ tetrahedra to form chains of alternating edge-shared $\mathrm{SiO}_{4}$ and $\mathrm{ZrO}_{8}$ polyhedra that run along the $c$-axis. The remaining four edges of the $\mathrm{SiO}_{4}$ tetrahedra are unshared and the $\mathrm{SiO}_{4}$ tetrahedra are isolated from one another.

The optimized structure of zircon obtained from the DFT simulation at static conditions $(0 \mathrm{~K}$, with no zero point vibrational effects included) and zero pressure exhibits unit-cell parameters that are about $0.6 \%$ larger than recent experimental values at room conditions (Finch et al. 2001; Kolesov et al. 2001; Finch and Hanchar 2003) and the Si-O bonds and the shorter $\mathrm{Zr}-\mathrm{O}$ bonds (around $2.15 \AA$ ) in the simulation are both about $0.7-0.8 \%$ longer than the experimentally determined values. This behavior is expected when GGA functionals are employed, and is probably due to the self-interaction error (Cremer 2001) as the overestimation of the volume of the core region where the electron correlation is large (due to the high electron density) is not perfectly corrected by the DFT functionals. However, since the core region plays no role in determining chemical properties of the system, this is not a problem. What is important for studying the phase transformation of zircon to reidite, which has the same primary coordination of $\mathrm{Si}$ and $\mathrm{Zr}$, is that the local structural distortions in zircon are well-reproduced by the DFT simulation. Thus, the $\mathrm{Zr}-\mathrm{O}$ bonds to the shared dodecahedral O-O edges with the $\mathrm{SiO}_{4}$ tetrahedra are $0.13 \AA$ longer than those to $\mathrm{O}$ not involved in edge-sharing with the $\mathrm{SiO}_{4}$, and the O-Si-O angle to the same shared edge is only $96.5^{\circ}$ (Fig. 2 ), which are within 2 e.s.d. values of the experimental values at room conditions (Finch et al. 2001; Kolesov et al. 2001).

\section{Zircon under hydrostatic pressure}

The simulation at $5 \mathrm{GPa}$, and the changes from the simulation at zero pressure (both at $0 \mathrm{~K}$ ), show the same approximately uniform compression of the structure reported in the only (to the authors' knowledge) experimental high-pressure structural study of zircon (Hazen and Finger 1979) that was limited to a maximum pressure of $4.8 \mathrm{GPa}$. The higher precision of the DFT simulations, together with the simulations to the highest pressure of $25 \mathrm{GPa}$, allow the static compression mechanisms to be de-

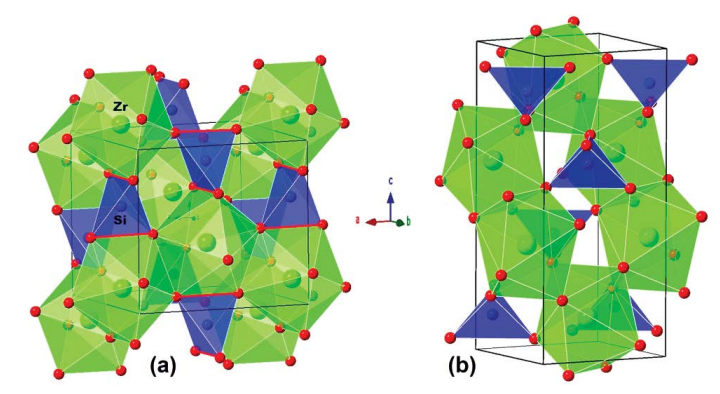

FIGURE 1. Polyhedral representations of the crystal structures of (a) zircon and (b) reidite drawn with CrystalMaker (2018). The shared O-O edges between the $\mathrm{ZrO}_{8}$ and the $\mathrm{SiO}_{4}$ polyhedra in zircon are highlighted in red. (Color online.) 
fined in more detail. The $\mathrm{O}-\mathrm{Si}-\mathrm{O}$ angles change by less than $1^{\circ}$ over this entire pressure range, meaning that the distortion of the $\mathrm{SiO}_{4}$ tetrahedra remains almost unchanged. However, the Si-O bond lengths shorten considerably, and the bulk modulus of the tetrahedra is 351(2) GPa. In contrast, the shorter $\mathrm{Zr}-\mathrm{O}$ bonds are significantly softer than the longer $\mathrm{Zr}-\mathrm{O}$ bonds, because the longer $\mathrm{Zr}-\mathrm{O}$ bonds are to the oxygen atoms involved in the shared polyhedral edge with the $\mathrm{SiO}_{4}$ tetrahedra, and are therefore stiffened by $\mathrm{Zr}$-Si repulsion (Hazen and Finger 1979). The overall bulk modulus of the $\mathrm{ZrO}_{8}$ polyhedra in zircon calculated from the DFT simulations is $209(1) \mathrm{GPa}$, so they are significantly softer than the $\mathrm{SiO}_{4}$ tetrahedra.

The isothermal Reuss bulk modulus of zircon obtained from fitting a third-order Birch-Murnaghan equation of state (BM3 EoS) to the unit-cell volumes of the static DFT simulations (i.e., without zero-point vibrational effects) at high pressures is 220.3(5) GPa, indicating that the compression of the $\mathrm{ZrO}_{8}$ polyhedra dominate the bulk properties of zircon, with a $K_{0}^{\prime}=4.71(4)$. The bulk modulus is lower than the value of 227(2) GPa at $0 \mathrm{~K}$ that can be derived from a complete analysis of all available experimental data (Zaffiro et al. 2018). The pressure derivative of the bulk modulus, $K_{0}^{\prime}$, cannot be reliably determined from currently available experimental data, and has been estimated to lie in the range 5 to 6.5 at $300 \mathrm{~K}$ (Zaffiro et al. 2018). The DFT simulations reproduce the correct sense of elastic anisotropy (Table 1) known from experimental data (Ozkan and Jamieson
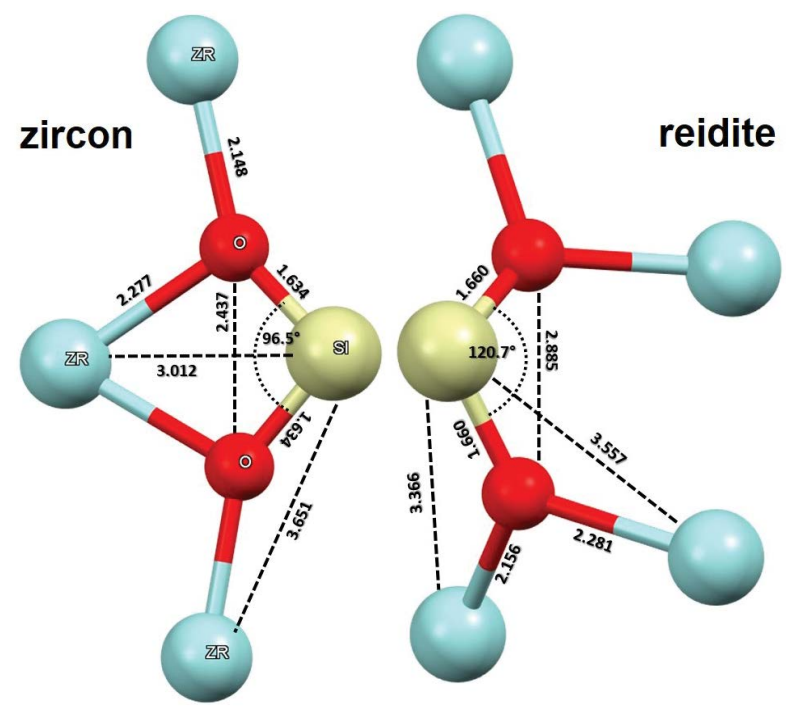

FIGURE 2. Interatomic distances (angstroms) and angles of zircon and reidite in the simulated structures at zero pressure. Only one-half of each $\mathrm{SiO}_{4}$ tetrahedron is shown for each polymorph. Note that in zircon two $\mathrm{O}$ atoms are shared by one $\mathrm{Si}$ and one $\mathrm{Zr}$ and form a shared polyhedral edge. (Color online.)
1978; Zaffiro et al. 2018) with the $c$-axis being significantly stiffer under compression than the $\boldsymbol{a}$-axis as a consequence of the chains of edge-sharing of the $\mathrm{SiO}_{4}$ and $\mathrm{ZrO}_{8}$ polyhedra that run parallel to the $c$-axis.

\section{Raman vibrational frequencies of zircon}

The experimental Raman shifts at $70 \mathrm{~K}$ reported by Syme et al. (1977) show a good agreement with the Raman active modes calculated at zero pressure and $0 \mathrm{~K}$ (Table 2). The calculated trends of the Raman shifts with pressure are in good agreement with recent experimental data up to $10 \mathrm{GPa}$ obtained from non-metamict single crystals under hydrostatic pressure (Pina Binvignat et al. 2018). That experimental study also confirmed that zircon does not undergo any phase transition under hydrostatic pressures up to $10 \mathrm{GPa}$ at room temperature. The wavenumbers of most of the Raman modes are predicted to increase with increasing pressure, meaning that $\partial \omega / \partial P$ is positive (Table 2 ), in agreement with the experimental data. As expected, bond lengths decrease as pressure (evaluated at the static level) is imposed on the crystal and this also changes the energetics of the crystal: the shortening of the interatomic distances increases the energy of the structure at the static equilibrium and also the restoring forces on the atoms, and therefore the vibrational frequencies. However, two Raman-active modes of zircon $\left[\mathrm{E}_{\mathrm{g} 1}(1)\right.$ at $\omega_{\mathrm{DFT}}=$ $197 \mathrm{~cm}^{-1}$ and $\mathrm{B}_{2 \mathrm{~g}}$ at $\omega_{\mathrm{DFT}}=250 \mathrm{~cm}^{-1}$ ] show the opposite behavior, with softening of the vibrational frequency with increasing pressure. This is also in agreement with the experiments as shown in Figure 3 and Table 2.

As displayed in the animated sketches of the vibrations of these two modes shown in Supplemental ${ }^{1}$ Figures S1 and S2 (see also Sheremetyeva et al. 2018), the specific atom displacements involved in these two modes are mainly rigid movements of the polyhedra that do not significantly modify the bond lengths. In the $\mathrm{B}_{2 \mathrm{~g}}$ mode the $\mathrm{Zr}^{4+}$ ions do not move appreciably, while the $\mathrm{SiO}_{4}$ units undergo a shearing motion that does not significantly

TABLE 2. Wavenumbers $(\omega)$ and their pressure derivatives $(\partial \omega / \partial P)$ of Raman-active modes of zircon

\begin{tabular}{|c|c|c|c|c|c|c|}
\hline \multirow[t]{3}{*}{ Mode } & \multicolumn{2}{|c|}{$\omega\left(\mathrm{cm}^{-1}\right)$} & \multicolumn{4}{|c|}{$\partial \omega / \partial P\left(\mathrm{~cm}^{-1} / \mathrm{GPa}\right)$} \\
\hline & \multirow{2}{*}{$\frac{\text { experimental }^{\mathrm{a}}}{T=70 \mathrm{~K}}$} & \multirow{2}{*}{$\begin{array}{c}\text { calculated } \\
0 \mathrm{~K} \\
P=0\end{array}$} & \multicolumn{2}{|c|}{ experimental $^{\mathrm{b}}$} & \multicolumn{2}{|c|}{ calculated } \\
\hline & & & $\begin{array}{c}T=298 \mathrm{~K}, \\
P=0\end{array}$ & $\begin{array}{c}\text { up to } \\
10 \mathrm{GPa}\end{array}$ & $\begin{array}{c}\text { up to } \\
10 \mathrm{GPa}\end{array}$ & $\begin{array}{c}\text { up to } \\
25 \mathrm{GPa} \\
\end{array}$ \\
\hline$A_{1 g}(1)$ & 441.5 & 439 & 439.6 & 1.44 & 1.50 & 1.37 \\
\hline$A_{1 g}(2)$ & 978 & 970 & 975.4 & 4.97 & 4.84 & 4.28 \\
\hline$B_{1 g}(1)$ & 216.5 & 216 & 215.1 & 1.27 & 1.37 & 1.12 \\
\hline $\mathrm{B}_{1 \mathrm{~g}}(2)$ & 395 & 387 & 394.0 & 1.86 & 2.08 & 1.86 \\
\hline$B_{1 g}(3)$ & 642 & 636 & - & - & 2.05 & 1.82 \\
\hline$B_{1 g}(4)$ & 1012.5 & 1015 & 1008.6 & 5.54 & 5.23 & 4.61 \\
\hline$B_{2 g}$ & 265 & 250 & - & - & -1.33 & -1.46 \\
\hline$E_{g}(1)$ & 202.5 & 197 & 202.6 & -0.56 & -0.56 & -0.81 \\
\hline$E_{g}(2)$ & 225.5 & 225 & 224.5 & 0.30 & 0.05 & 0.07 \\
\hline$E_{g}(3)$ & 360 & 341 & 357.9 & 4.27 & 4.57 & 3.92 \\
\hline$E_{g}(4)$ & 547 & 542 & - & - & 0.71 & 0.63 \\
\hline$\underline{E_{g}}(5)$ & 927 & 922 & - & - & 4.89 & 4.32 \\
\hline
\end{tabular}

ayme et al. (1977)

b Pina Binvignat et al. (2018).

TABLE 1. Calculated zircon and reidite EoS parameters

\begin{tabular}{|c|c|c|c|c|c|c|c|c|c|}
\hline & $V_{0}\left(\AA^{3}\right)$ & $K_{0}(\mathrm{GPa})$ & $K_{0}^{\prime}$ & $a_{0}(\AA)$ & $\mathrm{M}_{\mathrm{a} 0}(\mathrm{GPa})$ & $\mathrm{M}_{\mathrm{a} 0}^{\prime}$ & $C_{0}(\AA)$ & $\mathrm{M}_{\mathrm{co}}(\mathrm{GPa})$ & $\mathrm{M}_{\mathrm{c} 0}^{\prime}$ \\
\hline Zircon & $266.49(11)$ & $220.3(5)$ & $4.71(4)$ & $6.6514(2)$ & $551(2)$ & $15.8(2)$ & $6.0238(2)$ & $1050(1)$ & $5.3(2)$ \\
\hline Reidite & $239.57(6)$ & $241(5)$ & $4.7(6)$ & $4.76078(3)$ & $921(2)$ & $10.1(2)$ & $10.5700(2)$ & $501(1)$ & $16.1(2)$ \\
\hline
\end{tabular}

Note: Parameters are for Birch-Murnaghan third-order EoS, obtained by fitting the unit-cell volumes and cell parameters from the static DFT simulations up to 25 GPa for zircon, and to $17 \mathrm{GPa}$ for reidite. 


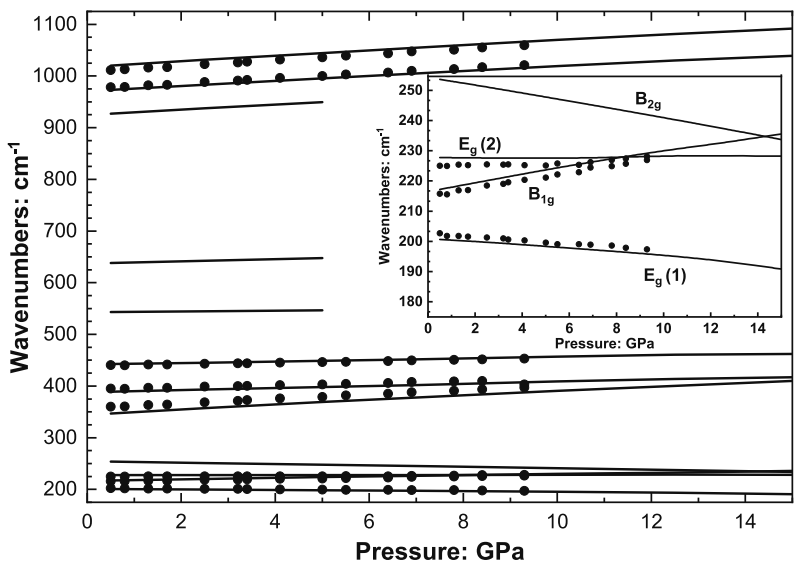

FIGURE 3. Calculated (lines) and experimental Raman shifts of zircon (Pina Binvignat et al. 2018, symbols) as a function of pressure. Some of the calculated Raman active modes are not observed in experiments because of their low intensities. The inset shows the softening of the $B_{2 g}$ and $\mathrm{E}_{\mathrm{g}}(1)$ modes with pressure.

modify the bond lengths. Similarly, the $\mathrm{E}_{\mathrm{g}}(1)$ mode consists of a rigid rotation around the $c$-axis of the $\mathrm{SiO}_{4}$ without changes in the $\mathrm{Si}-\mathrm{O}$ bond lengths. In both cases, the application of external hydrostatic pressure slightly reduces the force constants, resulting in a lowering of the normal mode wavenumber with a negative $\partial \omega / \partial P$ coefficient. In other words, the increase of the repulsion among the nuclei due to the volume contraction is dynamically partially compensated by the low-frequency $\mathrm{SiO}_{4}$-rotation modes, which facilitate the reduction of the $\mathrm{Zr}$-O-Si bond angles and the increase of internuclear distances of the static equilibrium configuration (see the discussion in Prencipe et al. 2011). As a consequence, the potential wells become shallower and the corresponding vibrational frequencies decrease as pressure increases.

In Table 2 we also report $\partial \omega / \partial P$ from our simulations up to $25 \mathrm{GPa}$, which shows that $\partial \omega / \partial P$ becomes more negative as pressure increases. However, none of the calculated frequencies of the Raman-active modes goes to zero, so this softening does not imply that the structure becomes dynamically unstable. Nonetheless, our calculations show that the lowest-frequency mode at $131 \mathrm{~cm}^{-1}$, which is a silent mode with $B_{1 \mathrm{u}}$ symmetry and thus not observable with conventional experimental Raman spectroscopy, softens completely to zero at around $20 \mathrm{GPa}$ (Fig. 4). Therefore, according to our calculations, if hydrostatic pressure conditions are maintained up to $20 \mathrm{GPa}$ at $0 \mathrm{~K}$ zircon undergoes a displacive phase transition. This phenomenon was already reported by Smirnov et al. (2008) in DFT simulations of zircon up to $70 \mathrm{GPa}$, but the issue was not further discussed.

\section{High-pressure-low-symmetry new polymorph}

Following the procedure used in Prencipe et al. (2011), the soft mode was analyzed by initially shifting the atoms of the unit cell along the eigenvector associated with the $\mathrm{B}_{1 \mathrm{u}}$ mode: $\overline{4} 2 \mathrm{~d}$ space group symmetry resulted. By optimizing the geometry in this space group and keeping the cell volume fixed at the value corresponding to the softening $\left(P=20 \mathrm{GPa}\right.$ and $\left.V=246.05 \AA^{3}\right)$, the optimized structure has a static energy lower than the one resulting from the optimization at the same cell volumes but

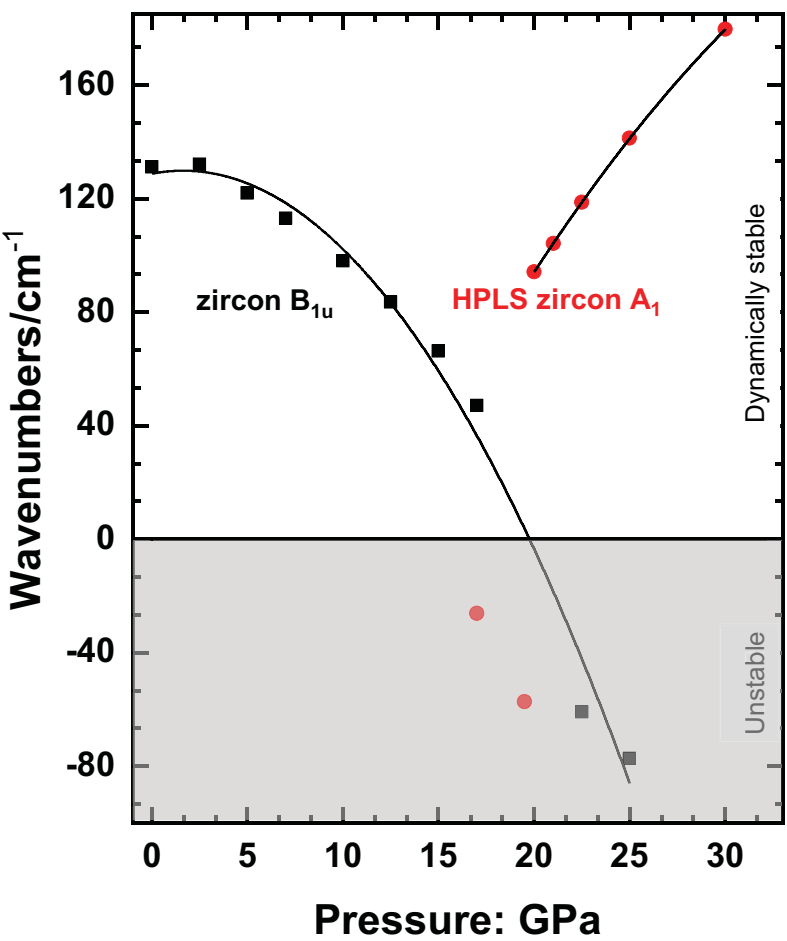

FIGURE 4. Variation of the wavenumber of the silent (i.e., neither Raman nor IR active) $B_{1 u}$ mode with pressure. Up to ca. $20 \mathrm{GPa}$ the mode frequency is positive but softens with pressure, and then becomes imaginary (plotted here as negative). In $\mathrm{HPLS}_{\mathrm{ZrSiO}}$ this mode becomes an $\mathrm{A}_{1}$ mode (circles). (Color online.)

in the $I 4_{1} /$ amd space group. Therefore, the new polymorph can be described as a high-pressure-low symmetry zircon (HPLS $\mathrm{ZrSiO}_{4}$ ), with a space group $I \overline{4} 2 d$ that is a direct subgroup of the space group $\mathrm{I}_{1} /$ amd of zircon. After re-optimization, the structure does not show any drastic structural reconstruction but subtle structural differences that break the symmetry of zircon. The new phase has very similar unit-cell parameters, $a$ $=6.399 \AA, c=5.881 \AA$ at $P=25 \mathrm{GPa}$, compared to values for zircon constrained to the higher symmetry at the same pressure, of $a=6.426 \AA, c=5.890 \AA$. Because the transition is driven by a soft mode and is displacive in character, the structural topology of the new polymorph is the same as that of zircon, containing $\mathrm{SiO}_{4}$ tetrahedra and $\mathrm{ZrO}_{8}$ dodecahedra, linked in the same way, so it is almost indistinguishable from zircon when viewed in the same orientation as zircon in Figure 1. Compared to zircon, all of the atoms of the high-pressure phase occupy Wyckoff positions of lower symmetry, and the $\overline{4}$ symmetry of the Si position that is $\overline{4} m 2$ in zircon allows the tetrahedra to be rotated compared to the fixed orientation in zircon. This is most obvious when the two structures are viewed down the $c$-axis (Fig. 5). The oxygen atom, therefore, is no longer required to occupy a position on a $\{100\}$ mirror plane (as in zircon) but occupies an unconstrained general equivalent position within the new polymorph. Comparison of the structures of zircon (constrained to $I 4_{1} /$ amd symmetry) and the relaxed structure of the new polymorph obtained from DFT simulations at the same pressures above the transition show that the individual bond lengths, $\mathrm{O}-\mathrm{Si}-\mathrm{O}$ angles, and $\mathrm{O}-\mathrm{O}$ distances 


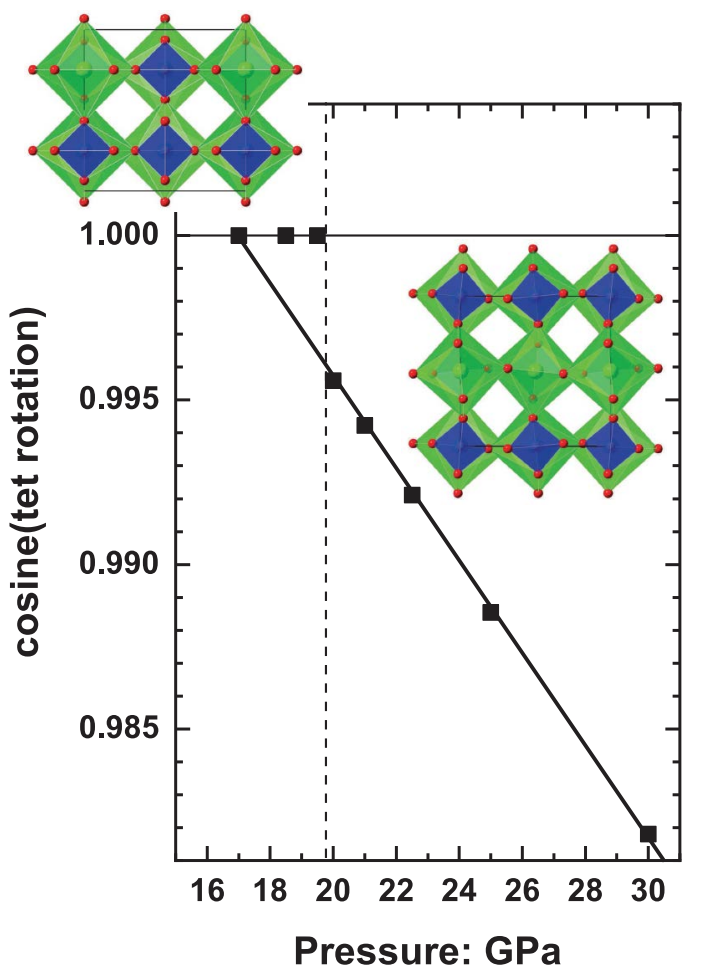

FIGURE 5. Variation with the pressure of the cosine of the tetrahedral rotation angle, with polyhedral representations of (left) zircon and (right) HPLS zircon viewed down their $\boldsymbol{c}$-axes. The tetrahedra are not rotated in zircon but become rotated in the HPLS phase. (Color online.)

within the $\mathrm{SiO}_{4}$ tetrahedra are identical within the uncertainties in the simulations. Therefore, the mechanism of the transition is one of rotation of the $\mathrm{SiO}_{4}$ tetrahedra around the $c$-axis of the structure, which is the same distortion that is generated by the soft $\mathrm{B}_{\mathrm{lu}}$ mode within the zircon structure (Fig. 5). This rotation alone, without any other distortion, leads to a reduction of the $a$ and $b$ cell parameters, a slight reduction in volume, and no change in the $c$ cell parameter. The simulated structures of the new polymorph however also show a small reduction in the $c$ cell parameter compared to zircon, which is due to small changes in the distortion of the $\mathrm{ZrO}_{8}$ dodecahedra. At $25 \mathrm{GPa}$, the new phase is $1 \%$ denser than zircon.

In summary, this phase transition is allowed by symmetry to be continuous in nature, and above $20 \mathrm{GPa}$ the spontaneous volume change (the volume difference between the HPLS phase and zircon at the same pressure) as well as the cosine of the tetrahedral rotation angle (Fig. 5) evolve linearly with pressure, which would be consistent with the transition being second-order in character (in the Landau sense, e.g., Carpenter et al. 1998). The wavenumber of the $\mathrm{B}_{1 \mathrm{u}}$ mode in zircon extrapolates to zero at ca. $19.5 \mathrm{GPa}$, and at $20 \mathrm{GPa}$ it becomes imaginary, showing that the zircon structure becomes dynamically unstable between 19.5 and $20 \mathrm{GPa}$ (Fig. 4). A simulation of the HPLS polymorph at $20 \mathrm{GPa}$ confirms this; the tetrahedral rotation angle is $5.2^{\circ}$ (clearly visible in Fig. 5), and at higher pressures the tetrahedral rotation angle continues to increase. The phonon frequencies of the new structure under hydrostatic pressures up to $30 \mathrm{GPa}$ remain positive, showing that it remains dynamically stable and does not undergo any further displacive-type phase transitions in this pressure range (Fig. 4). A similar behavior is seen for the Raman-active mode at $40 \mathrm{~cm}^{-1}$ in the high-symmetry phase of $\mathrm{Pb}_{3}(\mathrm{PO} 4)_{2}$ under high pressure (Mihailova et al. 2015). However, linear extrapolation of the volume strain of the HPLS phase to zero would suggest instead that the transition occurs not at 19.5 GPa but at a static pressure of $16.5-17 \mathrm{GPa}$ in our simulations, which then appears to indicate that the transition has a small $\Delta V$ step of $0.4 \%$ between 19.5 and $20 \mathrm{GPa}$. This apparent discrepancy with the character of the phase transition may be due to the difficulties within DFT of simulating small distortions of the structure near to the phase transition. We also note that the simulations are performed at static pressures and the true character and the transition pressure may be slightly different in zircon at finite temperatures. Only experimental data could resolve this question.

\section{Reidite structure and elasticity}

The only published experimental structure of reidite was based on a low-resolution powder diffraction measurement sample recovered from a high-pressure experiment (Kusaba et al. 1986); several computer simulations have subsequently confirmed the stability and structure type (Marqués et al. 2006; Smirnov et al. 2010; Dutta and Mandal 2012b; Du et al. 2012). Reidite has the scheelite structure type (Kusaba et al. 1986) and contains $\mathrm{SiO}_{4}$ tetrahedra linked only by corners to the three-dimensional framework of edge-sharing $\mathrm{ZrO}_{8}$ dodecahedra. In our DFT simulation at static equilibrium, the $\mathrm{SiO}_{4}$ tetrahedra have significantly longer bond lengths than in zircon ( $1.660 \AA$ compared to $1.634 \AA$ ), and the tetrahedra are flattened along the $c$-axis compared to those in zircon, where the elongation along the $c$-axis is due to the sharing of the tetrahedral edges with $\mathrm{ZrO}_{8}$ (see Figs. 1b and 2).

The simulations show that the $\mathrm{SiO}_{4}$ tetrahedra in reidite have a bulk modulus of $436 \mathrm{GPa}$, slightly stiffer than in zircon up to $17 \mathrm{GPa}$, and that the $\mathrm{ZrO}_{8}$ polyhedra are very similar in bulk compressibility to those in zircon (as for zircon, the results for reidite are from fits to static DFT simulations without zeropoint vibrational effects). In contrast to zircon, the longer of the two symmetry-independent $\mathrm{Zr}-\mathrm{O}$ bonds in reidite compresses significantly more than the shorter $\mathrm{Zr}-\mathrm{O}$ bond, which is a more normal behavior, and confirms the inferred influence of the shared O-O edges between the $\mathrm{ZrO}_{8}$ and $\mathrm{SiO}_{4}$ groups and the consequent $\mathrm{Zr}-\mathrm{Si}$ repulsion on the anisotropy of compression of zircon (Hazen and Finger 1979). The direction of the elastic anisotropy is reversed in reidite with respect to zircon, with the compressional modulus of the $c$-axis of reidite [501(1) GPa] being similar to the $\boldsymbol{a}$-axis of zircon [551(2) GPa]. The bulk modulus for reidite is determined to be 241(5) GPa [with $K_{0}^{\prime}$ $=4.7(6)$, Table 1], which is about $9 \%$ stiffer than zircon and consistent with the $9 \%$ density increase from zircon to reidite, as also estimated in previous DFT simulations (Marqués et al. 2006; Smirnov et al. 2008; Du et al. 2012; Dutta and Mandal $2012 \mathrm{~b}$ ). The experimental bulk modulus of reidite was reported to be $301.4 \pm 11.5 \mathrm{GPa}$ (Scott et al. 2001) and $392 \mathrm{GPa}$ (Ono et al. 2004a), but the latter is based on only six data points without a measurement of the recovered sample.

The calculated wavenumbers of the Raman active modes 
(Table 3) are in very good agreement with the data reported by Gucsik (2007). The $\partial \omega / \partial P$ slopes are all positive and thus all of the mode frequencies remain positive in the investigated pressure range, meaning that reidite remains dynamically stable. The modes that are more sensitive to pressure are those at higher wavenumbers, which are related to the symmetric and antisymmetric stretching of the $\mathrm{SiO}_{4}$. Moreover, the DFT simulations show that the doublet $\mathrm{B}_{\mathrm{g}}(3)$ and $\mathrm{E}_{\mathrm{g}}(3)$ that is present at $P=0$ converges to a singlet at $\mathrm{ca} .7 \mathrm{GPa}$.

\section{Zircon-reidite transition}

The space group of reidite, $I 4_{1} / a$, which is obviously a subgroup of the space group of zircon, $I 4_{1} / a m d$, when referred to the same unit cell and orientation, led several authors to assume that reidite (and scheelite structures in general) is a distorted form of the zircon structure and can be obtained by a displacive-type distortion of the zircon structure (e.g., Liu 1979; Kusaba et al. 1986; Knittle and Williams 1993; Glass and Liu 2001). This is not correct because the orientation of the symmetry elements with respect to the structural elements is different in the two phases. Structurally, the unit cell of reidite is rotated $45^{\circ}$ around the $c$ axis with respect to that of zircon (Fig. 1), and the relationship between the unit-cell parameters is $a_{r} \sim a_{z} \sqrt{2}$. This means that the directions of translation of the $a$ glides in reidite and zircon are also at $45^{\circ}$ to one another. The space group of zircon, $I 4_{1} / \mathrm{amd}$, does not contain $a$-glides with translations in the direction of the glides in reidite. Similarly, the (very approximate) doubling of the $c$-lattice parameter on going from zircon to reidite means that the elements of the $4_{1}$ symmetry operator in reidite are not present in zircon. The consequence of this symmetry relationship is that the topology of the polyhedral linkages in the structures of zircon and reidite are different, and this difference is the major cause for the large density and volume contrast between the two phases. Because the $\mathrm{SiO}_{4}$ tetrahedra in zircon share two edges with the $\mathrm{ZrO}_{8}$ dodecahedra, each silicon atom has six zircon atoms in its secondary coordination (Fig. 2). In the room-pressure simulation, two $\mathrm{Zr}$ atoms are at a distance of $3.01 \AA$ from each $\mathrm{Si}$ atom across the shared edges, and four at a distance of $3.65 \AA$. The average $\mathrm{Si}-\mathrm{Zr}$ distance is $3.44 \AA$. In reidite, there is only corner-sharing between the $\mathrm{SiO}_{4}$ and $\mathrm{ZrO}_{8}$ polyhedra, with each oxygen bonded to one $\mathrm{Si}$ atom and two $\mathrm{Zr}$ atoms. Each $\mathrm{Si}$ atom

TABLE 3. Wavenumbers $(\omega)$ and their pressure derivatives $(\partial \omega / \partial P)$ of Raman-active modes of reidite

\begin{tabular}{lccc}
\hline Mode & $\begin{array}{c}\text { Experimental }^{\mathrm{a}} \\
T=298 \mathrm{~K}\end{array}$ & $\begin{array}{c}\text { Calculated } \\
T=0 \mathrm{~K}\end{array}$ & $\partial \omega / \partial P$ \\
\hline $\mathrm{Ag}(1)$ & 327 & 326 & 1.05 \\
$\mathrm{Ag}(2)$ & 406 & 409 & 0.53 \\
$\mathrm{Ag}(3)$ & - & 861 & 1.29 \\
$\mathrm{Bg}(1)$ & 238 & 242 & 0.71 \\
$\mathrm{Bg}(2)$ & 353 & 350 & 2.70 \\
$\mathrm{Bg} \mathrm{(3)}$ & 464 & 465 & 1.80 \\
$\mathrm{Bg}(4)$ & 610 & 608 & 2.19 \\
$\mathrm{Bg} \mathrm{(5)}$ & 847 & 852 & 1.64 \\
$\mathrm{Eg}(1)$ & 205 & 209 & 2.05 \\
Eg (2) & 297 & 300 & 1.90 \\
Eg (3) & - & 458 & 4.18 \\
Eg (4) & 558 & 558 & 3.42 \\
Eg (5) & 887 & 891 & 4.51 \\
\hline Notes: Calculated slopes are from simulations up to a maximum pressure of \\
17 GPa. \\
a Gucsik (2007).
\end{tabular}

in the structure of reidite, therefore, has eight $\mathrm{Zr}$ neighbors, four at $3.37 \AA$ and four at $3.56 \AA$ at room pressure. The average $\mathrm{Si}-\mathrm{Zr}$ distance in reidite, $3.46 \AA$ is thus almost the same as in zircon, but the density of reidite is much greater because the secondary (Si to $\mathrm{Zr}$ ) coordination has increased from 6 to 8 (see Fig. 1).

Consequently, zircon undergoes a significant structural rearrangement when it transforms to its high-pressure polymorph reidite. The transformation is reconstructive and will occur only when a substantial energy barrier is overcome, either by high-temperature or significant over-stepping of the boundary in pressure, or a combination of the two. Calculation of the enthalpies $H=U+P V$ of the two polymorphs by combining the internal energy $U$, pressure $P$ and volume $V$ from the DFT simulations, shows that reidite becomes energetically more stable than zircon above a pressure of 9.13(1) GPa (Fig. 6) at $0 \mathrm{~K}$. This is not dissimilar to experiments. The experimental Clapeyron slope (Ono et al. 2004b) $\partial P / \partial T$ is zero or slightly positive, and extrapolation of the experimental results to $0 \mathrm{~K}$ would place the phase transition pressure between 6 and $8 \mathrm{GPa}$.

\section{IMPLICATIONS}

The DFT simulations can now explain the various experimental data on zircon and its transformations at high pressure. The calculated $P$ - $V$ curve from DFT is in good agreement with the data reported by Ono et al. (2004a) on quenched synthetic reidite samples as well as the results from the in situ highpressure study of zircon by Van Westrenen et al. (2004) (Fig. 7). The deviation to lower volumes seen above $19.7 \mathrm{GPa}$ in the data of Van Westrenen et al. (2004) is now seen to be the consequence of the displacive phase transition to the new "highpressure-low-symmetry" (HPLS) zircon phase that we have discovered in this DFT study. Raman spectra of the recovered sample from this experiment unequivocally show reidite so this suggests that, due to the sluggish character of the zircon to reidite transition, at high pressures the sample actually con-

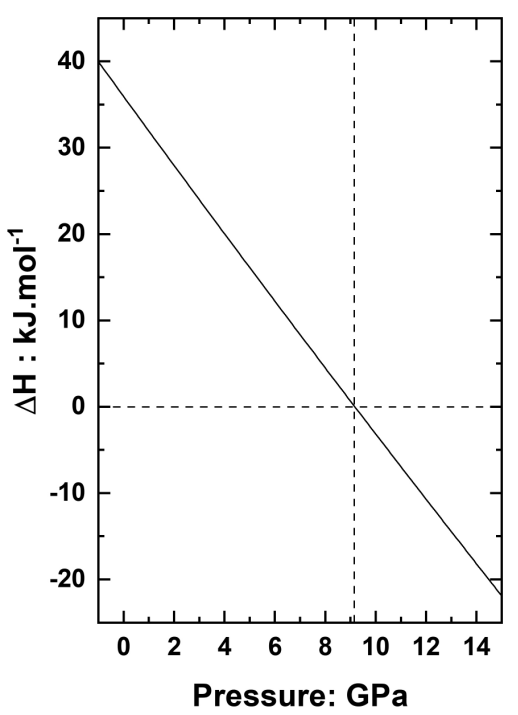

FIGURE 6. Variation of the enthalpy change $\Delta H$ for the zircon to reidite transition with pressure calculated from DFT at $0 \mathrm{~K}$, showing that the equilibrium transition pressure is 9.13(1) GPa. 


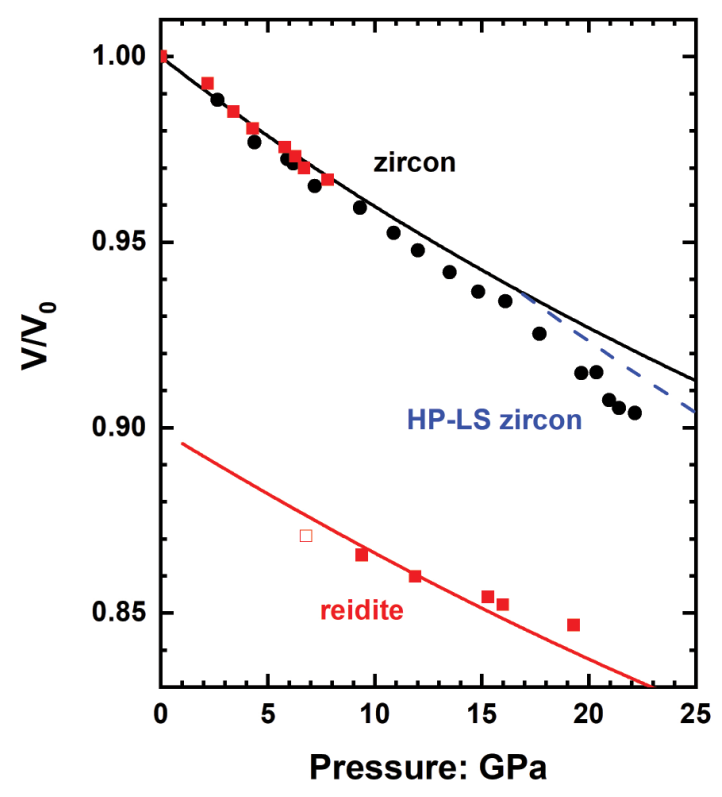

FIGURE 7. $P-V$ curves of the three polymorphs calculated by DFT at $0 \mathrm{~K}$ (lines) and experimental data at $300 \mathrm{~K}$ (red symbols, Ono et al. 2004a; black symbols, Van Westrenen et al. 2004). The deflection above $19 \mathrm{GPa}$ in the experimental data for zircon is in agreement with the smaller volume of the HPLS phase. (Color online.)

tained HPLS zircon plus an amount of reidite too small to be detected by diffraction. This shows that compression at room temperature and above $20 \mathrm{GPa}$ is sufficient to overcome the activation barrier for the zircon to reidite transformation and that at high pressures the sample will consist of a mixture of the HPLS zircon phase that has partially transformed to reidite. On pressure release, the HPLS zircon will transform back to normal zircon, while the reidite may not so that recovered samples consist of a mixture of reidite and zircon.

The DFT simulations of the Raman spectra of all three polymorphs allow us to give some guidelines as to which peaks in experimental Raman spectra are diagnostic for the different phases of $\mathrm{ZrSiO}_{4}$. The simulation of zircon at high pressure (e.g., 19.5 GPa) shows that peaks shift toward higher wavenumbers (Fig. 8), while the mode $\mathrm{E}_{\mathrm{g}}(1)$ shifts to lower wavenumbers under pressure, as we discussed in detail above. Above ca. $20 \mathrm{GPa}$ zircon is no longer stable and the symmetry is broken, resulting in the HPLS phase. At $20 \mathrm{GPa}$, according to the irreducible representations of point groups (for the $\Gamma$ point) the $B_{1 u}$ mode that is silent for the $4 / \mathrm{mmm}$ point group of zircon, turns into an $A_{1}$ symmetry mode for the $\overline{4} 2 \mathrm{~m}$ point group symmetry of the HPLS phase, which is Raman active. This mode has a high intensity even with random polarization as shown in Figure 8 and occurs at $94 \mathrm{~cm}^{-1}$ at $P=20 \mathrm{GPa}$. Supplemental ${ }^{1}$ Tables S1-S3 list the relative intensities of the Raman peaks of all three polymorphs simulated for single crystals and polycrystalline powders. Therefore, the HPLS phase can be distinguished from zircon in situ in high-pressure experiments by making Raman measurements in the low wavenumbers range (below $200 \mathrm{~cm}^{-1}$ ), where the peak at $94 \mathrm{~cm}^{-1}$ does not overlap with any peaks of reidite or zircon.

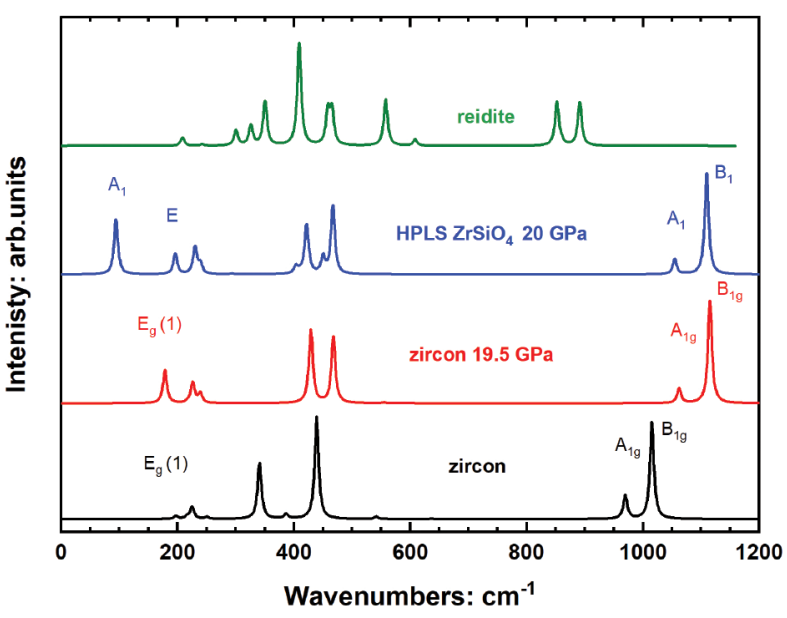

FigURE 8. Calculated Raman spectra of the three polymorphs: the spectra are simulated for a polycrystalline powder without any polarization. The Raman intensities are calculated at $298 \mathrm{~K}$ and with a wavelength excitation of $532 \mathrm{~nm}$. Calculated intensities for oriented single crystals in different scattering geometries are given in the Supplemental ${ }^{1}$ Tables S1, S2, and S3. (Color online.)

\section{FUNDING AND ACKNOWLEDGMENTS}

This work was supported by ERC starting grant 714936 "True Depths," the Italian Ministry for Research and University (MIUR) SIR grant "MILE DEEp" (RBSI140351) and the MIUR FARE research grant R164WEJAHH, all to Matteo Alvaro. We thank Wim van Westrenen and an anonymous reviewer for their comments on the manuscript.

\section{REFERENCES CITED}

Aliatis, I., Lambruschi, E., Mantovani, L., Bersani, D., Andò, S., Diego Gatta G., Gentile, P., Salvioli-Mariani, E., Prencipe, M., Tribaudino, M., Lottici, P.P. (2015) A comparison between ab initio calculated and measured Raman spectrum of triclinic albite $\left(\mathrm{NaAlSi}_{3} \mathrm{O}_{8}\right)$. Journal of Raman Spectroscopy, 46, 501-508.

Angel, R.J., Gonzalez-Platas, J., and Alvaro, M. (2014) EosFit7c and a Fortran module (library) for equation of state calculations. Zeitschrift für Kristallographie, 229, 405-419.

Carpenter, M.A., Salje, E.K.H., and Graeme-Barber, A. (1998) Spontaneous strain as a determinant of thermodynamic properties for phase transitions in minerals. European Journal of Mineralogy, 10, 621-691.

Cavosie, A.J., Erickson, T.M., and Timms, N.E. (2015) Nanoscale records of ancient shock deformation: reidite $\left(\mathrm{ZrSiO}_{4}\right)$ in sandstone at the Ordovician Rock Elm impact crater. Geology, 43, 315-318.

Cavosie, A.J., Timms, N.E., Erickson, T.M., and Koeberl, C. (2018) New clues from Earth's most elusive impact crater: evidence of reidite in Australasian tektites from Thailand. Geology, 46, 203-206.

Chen, M., Yin, F., Li, X., Xie, X., Xiao, W., and Tan, D. (2013) Natural occurrence of reidite in the Xiuyan crater of China. Meteoritics \& Planetary Science, 48, 796-805.

Civalleri, B., D'Arco, P., Orlando, R., Saunders, V.R., and Dovesi, R. (2001) Hartree-Fock geometry optimisation of periodic systems with the crystal code. Chemical Physics Letters, 348, 131-138.

Cremer, D. (2001) Density functional theory: coverage of dynamic and nondynamic electron correlation effects. Molecular Physics, 99, 1899-1940.

CrystalMaker (2018) CrystalMaker, a crystal \& molecular structures modelling program for Mac \& Windows, www.crystalmaker.com. CrystalMaker Software, Oxford, U.K.

Doll, K., Saunders, V.R., and Harrison, N.M. (2001) Analytical Hartree-Fock gradients for periodic systems. International Journal of Quantum Chemistry, $82,1-31$.

Dovesi, R., Orlando, R., Erba, A., Zicovich-Wilson, C. M., Civalleri, B., Casassa, S., Maschio, L., Ferrabone, M., De La Pierre, M., D’Arco, P., Noel, Y., Causà, M., Rérat, M., and Kirtman, B. (2014) CRYSTAL14: A program for the ab initio investigation of crystalline solids. International Journal of Quantum Chemistry, 114, 1287-1317.

Dovesi, R., Erba, A., Orlando, R., Zicovich-Wilson, C.M., Civalleri, B., Maschio, L., Rérat, M., Casassa, S., Baima, J., Salustro, S., and Kirtman, B. (2018) 
Quantum-mechanical condensed matter simulations with CRYSTAL. Wiley Interdisciplinary Reviews: Computational Molecular Science, e1360.

Du, J., Devanathan, R., René Corrales, L., and Weber, W.J. (2012) First-principles calculations of the electronic structure, phase transition and properties of $\mathrm{ZrSiO}_{4}$ polymorphs. Computational and Theoretical Chemistry, 987, 62-70.

Dutta, R., and Mandal, N. (2012a) Effects of pressure on the elasticity and stability of zircon $\left(\mathrm{ZrSiO}_{4}\right)$ : First-principle investigations. Computational Materials Science, 54, 157-164.

Dutta, R., and Mandal, N. (2012b) Structure, elasticity and stability of reidite $\left(\mathrm{ZrSiO}_{4}\right)$ under hydrostatic pressure: A density functional study. Materials Chemistry and Physics, 135, 322-329.

Ferrero, M., Rérat, M., Orlando, R., Dovesi, R., and Bush, I.J. (2008) Coupled perturbed Kohn-Sham calculation of static polarizabilities of periodic compounds. In Journal of Physics: Conference Series Vol. 117, 012016. IOP Publishing.

Finch, R.J., and Hanchar, J.M. (2003) Structure and chemistry of zircon and zircon-group minerals. Reviews in Mineralogy and Geochemistry, 53, 1-25.

Finch, R.J., Hanchar, J.M., Hoskin, P.W.O., and Burns, P.C. (2001) Rare-earth elements in synthetic zircon: Part 2. A single-crystal X-ray study of xenotime substitution. American Mineralogist, 86, 681-689.

French, B.M. (1998) Traces of catastrophe: A handbook of shock-metamorphic effects in terrestrial meteorite impact structures, LPI Contribution, $954 \mathrm{p}$

French, B.M., and Koeberl, C. (2010) The convincing identification of terrestrial meteorite impact structures: What works, what doesn't, and why. Earth-Science Reviews, 98, 123-170.

Glass, B.P., and Liu, S. (2001) Discovery of high-pressure $\mathrm{ZrSiO}_{4}$ polymorph in naturally occurring shock-metamorphosed zircons. Geology, 29, 371-373.

Glass, B.P., Liu, S., and Leavens, P.B. (2002) Reidite: An impact-produced high-pressure polymorph of zircon found in marine sediments. American Mineralogist, 87, 562-565.

Gucsik, A. (2007) Micro-Raman spectroscopy of reidite as an impact-induced high pressure polymorph of zircon: experimental investigation and attempt to application. Acta Mineralogica Petrographica, 47, 17-24.

Gucsik, A., Zhang, M., Koeberl, C., Salje, E.K.H., Redfern, S.A.T., and Pruneda, J.M. (2004) Infrared and Raman spectra of $\mathrm{ZrSiO}_{4}$ experimentally shocked at high pressures. Mineralogical Magazine, 68, 801-811.

Hazen, R.M., and Finger, L.M. (1979) Crystal structure and compressibility of zircon at high pressure. American Mineralogist, 64, 196-201.

Knittle, E., and Williams, Q. (1993) High-pressure Raman spectroscopy of $\mathrm{ZrSiO}_{4}$ : observation of the zircon to scheelite transition at $300 \mathrm{~K}$. American Mineralogist, 78, 245-252.

Kolesov, B.A., Geiger, C.A., and Armbruster, T. (2001) The dynamic properties of zircon studied by single-crystal X-ray diffraction and Raman spectroscopy. European Journal of Mineralogy, 13, 939-948.

Kusaba, K., Yag, T., Kikuchi, M., and Syono, Y. (1986) Structural considerations on the mechanism of the shock-induced zircon-scheelite transition in $\mathrm{ZrSiO}_{4}$. Journal of Physics and Chemistry of Solids, 47, 675.

Langenhorst, F., and Deutsch, A. (2012) Shock metamorphism of minerals. Elements, 8, 31-36.

Lee, C.T., Yang, W.T., and Parr, R.G. (1988) Development of the Colle-Salvetti correlation-energy formula into a functional of the electron-density. Physical Review B, 37, 785-789.

Leroux, H., Reimold, W.U., Koeberl, C., Hornemann, U., and Doukhan, J.C. (1999) Experimental shock deformation in zircon: a transmission electron microscopic study. Earth and Planetary Science Letters, 169, 291-301.

Liu, L.G. (1979) High-pressure phase transformations in baddeleyite and zircon, with geophysical implications. Earth and Planetary Science Letters, 44, 390-396.

Marqués, M., Flórez, M., Recio, J.M., Gerward, L., and Olsen, J.S. (2006) Structure and stability of $\mathrm{ZrSiO}_{4}$ under hydrostatic pressure. Physical Review B-Condensed Matter and Materials Physics, 74, 1-9.

Maschio, L., Kirtman, B., Salustro, S., Zicovich-Wilson, C.M., Orlando, R., and Dovesi, R. (2013) Raman spectrum of pyrope garnet. A quantum mechanical simulation of frequencies, intensities, and isotope shifts. Journal of Physical Chemistry A, 117, 11464-11471.

Mihailova, B., Angel, R.J., Waeselmann, N., Maier, B.J., Paulmann, C., and Bismayer, U. (2015) Pressure-induced transformation processes in ferroelastic $\mathrm{Pb}_{3}\left(\mathrm{P}_{1-\mathrm{x}} \mathrm{As}_{\mathrm{x}} \mathrm{O}_{4}\right)_{2}, \mathrm{x}=0$ and 0.80 . Zeitschrift für Kristallographie-Crystalline Materials, 230, 593-603.

Morozova, I. (2015) Strength study of zircon under high pressure. Master thesis, University of Western Ontario.

Ono, S., Tange, Y., Katayama, I., and Kikegawa, T. (2004a) Equations of state of $\mathrm{ZrSiO}_{4}$ phases in the upper mantle. American Mineralogist, 89, 185-188.

Ono, S., Funakoshi, K., Nakajima, Y., Tange, Y., and Katsura, T. (2004b) Phase transition of zircon at high P-T conditions. Contributions to Mineralogy and Petrology, 147, 505-509.

Ozkan, H., and Jamieson, J.C. (1978) Pressure dependence of the elastic constants of nonmetamict zircon. Physics and Chemestry of Minerals, 224, 215-224.

Pascale, F., Zicovich-Wilson, C.M., Lopez Gejo, F., Civalleri, B., Orlando, R., and
Dovesi, R.T. (2004) The calculation of the vibrational frequencies of crystalline compounds and its implementation in the CRYSTAL code. Journal of Computational Chemistry, 25, 888-897.

Pina Binvignat, F.A., Malcherek, T., Angel, R.J., Paulmann, C., Schlüter, J., and Mihailova, B. (2018) Effect of radiation-induced structural damage on the structural response of zircon to high pressures. Physics and Chemistry of Minerals, 45, 981-993.

Prencipe, M. (2012) Simulation of vibrational spectra of crystals by ab initio calculations: An invaluable aid in the assignment and interpretation of the Raman signals. The case of jadeite $\left(\mathrm{NaAlSi}_{2} \mathrm{O}_{6}\right)$. Journal of Raman Spectroscopy, 43, 1567-1569.

Prencipe, M., Scanavino, I., Nestola, F., and Merlini, M. (2011) High-pressure thermo-elastic properties of beryl $\left(\mathrm{Al}_{4} \mathrm{Be}_{6} \mathrm{Si}_{12} \mathrm{O}_{36}\right)$ from ab initio calculations, and observations about the source of thermal expansion. Physics and Chemistry of Minerals, 38(3), 223-239.

Reddy, S.M., Johnson, T.E., Fischer, S., Rickard, W.D.A., and Taylor, R.J.M (2015) Precambrian reidite discovered in shocked zircon from the Stac Fada impactite, Scotland. Geology, 43, 899-902.

Reid, A.F., and Ringwood, A.E. (1969) Newly observed high pressure transformations in $\mathrm{Mn}_{3} \mathrm{O}_{4}, \mathrm{CaAl}_{2} \mathrm{O}_{4}$, and $\mathrm{ZrSiO}_{4}$. Earth and Planetary Science Letters, 6, 205-208.

Scott, H.P., Williams, Q., and Knittle, E. (2002) Ultralow compressibility silicate without highly coordinated silicon. Physical Review Letters, 88, 015506.

Sheremetyeva, N., Cherniak, D.J., Watson, E.B., and Meunier, V. (2018) Effect of pressure on the Raman-active modes of zircon $\left(\mathrm{ZrSiO}_{4}\right)$ : a first-principles study. Physics and Chemistry of Minerals, 45, 173-184.

Singleton, A.C., Osinski, G.R., and Shieh, S.R. (2015) Microscopic effects of shock metamorphism in zircons from the Haughton impact structure, Canada. Geological Society of America Special Papers, 518, 135-148.

Smirnov, M.B., Mirgorodsky, A.P., Kazimirov, V.Y., and Guinebretière, R. (2008) Bond-switching mechanism for the zircon-scheelite phase transition. Physical Review B-Condensed Matter and Materials Physics, 78, 1-11.

Smirnov, M.B., Sukhomlinov, S.V., and Smirnov, K.S. (2010) Vibrational spectrum of reidite $\mathrm{ZrSiO}_{4}$ from first principles. Physical Review B, 82, 094307.

Sophia, G., Baranek, P., Sarrazin, C., Rérat, M., and Dovesi, R. (2013) Firstprinciples study of the mechanisms of the pressure-induced dielectric anomalies in ferroelectric perovskites. Phase Transitions, 86, 1069-1084.

Stangarone, C., Tribaudino, M., Prencipe, M., and Lottici, P.P. (2016) Raman modes in Pbca enstatite $\left(\mathrm{Mg}_{2} \mathrm{Si}_{2} \mathrm{O}_{6}\right)$ : an assignment by quantum mechanical calculation to interpret experimental results. Journal of Raman Spectroscopy, $47,1247-1258$

Stangarone, C., Böttger, U., Bersani, D., Tribaudino, M., and Prencipe, M. (2017) $\mathrm{Ab}$ initio simulations and experimental Raman spectra of $\mathrm{Mg}_{2} \mathrm{SiO}_{4}$ forsterite to simulate Mars surface environmental conditions. Journal of Raman Spectroscopy, 48, 1528-1535.

Syme, R.W.G., Lockwood, D.J., and Kerr, H.J. (1977) Raman spectrum of synthetic zircon $\left(\mathrm{ZrSiO}_{4}\right)$ and thorite $\left(\mathrm{ThSiO}_{4}\right)$. Journal of Physics C: Solid State Physics, 10, 1335-1348.

Valenzano, L., Torres, F.J., Doll, K., Pascale, F., Zicovich-Wilson, C.M., and Dovesi, R. (2006) Ab initio study of the vibrational spectrum and related properties of crystalline compounds; the case of $\mathrm{CaCO}_{3}$ calcite. Zeitschrift für Physikalische Chemie, 220, 893-912.

Van Westrenen, W., Frank, M.R., Hanchar, J.M., Fei, Y., Finch, R.J., and Zha, C.S. (2004) In situ determination of the compressibility of synthetic pure zircon $\left(\mathrm{ZrSiO}_{4}\right)$ and the onset of the zircon-reidite phase transition. American Mineralogist, 89, 197-203.

Wittmann, A., and Reimold, W. (2009) The record of ground zero in the Chesapeake Bay impact crater-Suevites and related rocks. GSA Special Paper, 458, 349-376.

Wittmann, A., Kenkmann, T., Schmitt, R.T., and Stöffler, D. (2006) Shockmetamorphosed zircon in terrestrial impact craters. Meteoritics and Planetary Science, 41, 433-454.

Wu, Z., and Cohen, R.E. (2005) Generalized gradient approximation made more accurate for solids. Physical Review B, 73, 235116.

Zaffiro, G., Angel, R.J., Alvaro, M., Prencipe, M., and Stangarone, C. (2018) P-V-T-Ks equations of state for zircon and rutile. Geophysical Research Abstract, vol. 20,6952.

MANUSCRIPT RECEIVED SEPTEMBER 27, 2018

MANUSCRIPT ACCEPTED MARCH 1, 2019

MANUSCRIPT HANDLED BY KEITH REFSON

\section{Endnote:}

${ }^{1}$ Deposit item AM-19-66827, Supplemental Material and CIFs. Deposit items are free to all readers and found on the MSA website, via the specific issue's Table of Contents (go to http://www.minsocam.org/MSA/AmMin/TOC/2019/Jun2019_data/ Jun2019 data.html). 